\title{
PROCEDURE AND CONSTRUCTION OF ROAD UNDER BRIDGE BY BOX PUSHING METHOD
}

\author{
Ranjeet. P ${ }^{1}$, D.V.S. Narshima Rao ${ }^{2}$, Mohd Akram Ullah Khan ${ }^{3}$, K. Hanumanthu ${ }^{4}$ \\ ${ }^{1}$ Assistant Professor, Civil Department, GNITC, Telangana, India. \\ ${ }^{2}$ Assistant Professor, Civil Department, GNITC, Telangana, India. \\ ${ }^{3}$ Assistant Professor, Civil Department, GNITC, Telangana, India. \\ ${ }^{4}$ Assistant Professor, Civil Department, GNITC, Telangana, India.
}

\begin{abstract}
The intersection of railway track and the road at the same level is referred to a level crossing. In the urban areas the level crossing are generally monitored by qualified railway personnel who monitor the train movement and close the level crossing gate to stop the interfering road traffic but such closing of gates leads to congestion in road traffic and also causes loss of time to road users. Road under bridge and road over bridge are considered as solutions for avoiding level crossings of roads and railway track. There are 3 main methods in construction of road under bridge. Box pushing method, Cut and cover method, Rolling technique using RH girder. In this we discuss about the implements, soil friction, effects required, capacity of jacks and there uses, skew angles and at square angles.
\end{abstract}

Keywords: Road Under Bridge, Level Crossing, Box Pushing Method and RUB etc...

\section{INTRODUCTION}

Level crossings continue to be the weakest link, most unsafe element and source of accidents on Railway track from safety point of view. Due to increase in train speed and nonobservance of rules by road users, these are more critical. Although, the total number of accidents occurring on the Indian Railways is showing a progressive decline, level crossing accidents are still hovering at around the same level. With the growing impetus on urbanization and increase in the road network, the demand for providing road under bridges by elimination of level crossings is on the rise. To construct such openings with least disruption not only to the train services but also to the public and related infrastructure is a challenge to the Railway Engineers

\subsection{Necessity for Construction of Road Under}

\section{Bridge}

With the introduction of high speed trains on several routes and the plans of the Indian Railways to join the high speed club shortly, the safety aspect / elimination of level crossings must be studied in detail since the speed of the approaching train will be much higher and so will be the danger of accident at LC's, despite the fact that most of the accidents at level crossings are due to the carelessness of the road users, Railways have to be more pro-active to improve the safety.

With the continuous increase in the rail traffic as well as road traffic, the interface between rail and road traffic is bound to multiply as we proceed towards becoming a developed nation. Grade separators i.e. Road over bridges / Road under bridges / subways, therefore, shall not only ensure the best safety standards but also shall be cost effective in the long run.

One of the measures initiated to reduce the number of level crossings is replacement of level crossings with ROB's / RUB`s and limited height subways which eliminates accidents at level crossings besides significant improvement in operational benefits and enhanced safety.

Construction of RUB`s offers excellent operational leverage both for Railways and Highways and offers win - win situation for all end users i.e. pedestrian traffic, road traffic and rail traffic. It is the safest techno - socio - economic solution to the existing problem at rail - road interface.

\subsection{Methods of Elimination of Level Crossing 'S}

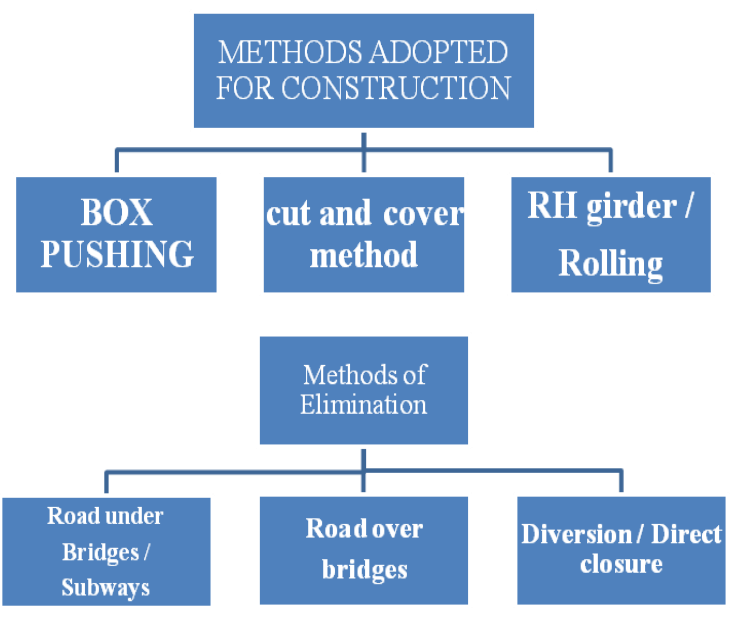

Flow Chart -1: Methods of elimination of level crossings 
Before taking up the work followings are to be ensured:Feasible Level Crossing`s to be identified, State Government consent to be obtained, Sanction of work, Preparation of GAD, detailed estimate, tendering etc. CRS sanction to be obtained, Execution of the work

\section{ROAD OVER BRIDGES}

A bridge is a span structure is built to physical obstacles such as a body of water, valley, or road, for the purpose of passage over the obstacle. Designs of bridges vary depending on the function of the bridge, the nature of the terrain where the bridge is constructed, the material used to make it and the funds available to build it.

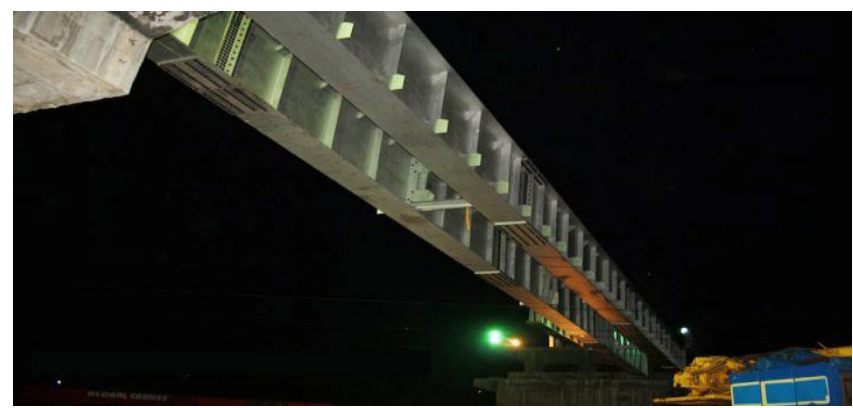

Fig -1: I section girder on ROB.

\section{ROAD UNDER BRIDGES}

The movement of traffic in both perpendicular directions which is above and below is said to be road under bridge. This may vary in location. The road above the water bodies is also said to be road under bridge

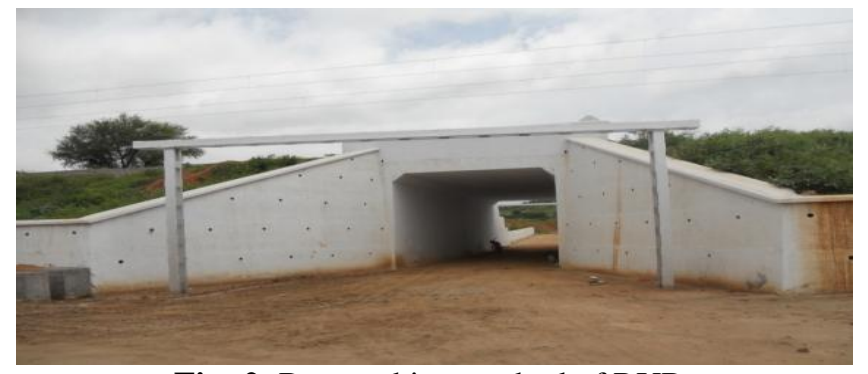

Fig -2: Box pushing method of RUB.

\section{METHODS OF CONSTRUCTION}

Flow Chart -2: Methods of Construction ROB and RUB Out of the above three methods, Box pushing is the latest and is widely used in our country. The advent of Box pushing technique has revolutionized the construction world and proven to be an ideal and the best as it is non intrusive, best suited for construction of underpasses and subways in urban areas in a manner that minimizes disruption to road traffic, constraints of space and time.

\subsection{Procedure of Box Pushing}

A properly designed RCC thrust bed is casted at appropriate location. Generally the top layer of $50 \mathrm{~mm}$ is finished with screwing layer to obtain a perfect level surface. This thrust bed along with the connected thrust walls and shear keys serves the purpose of forming the base to the casting of the box segments and also enables jacking of the segments. It acts as a medium to transfer the entire jacking force into the ground. The auxiliary thrust bed also may be constructed depending upon site requirement, which in turn helps in saving of reinforcement, time, labor and expenditure.
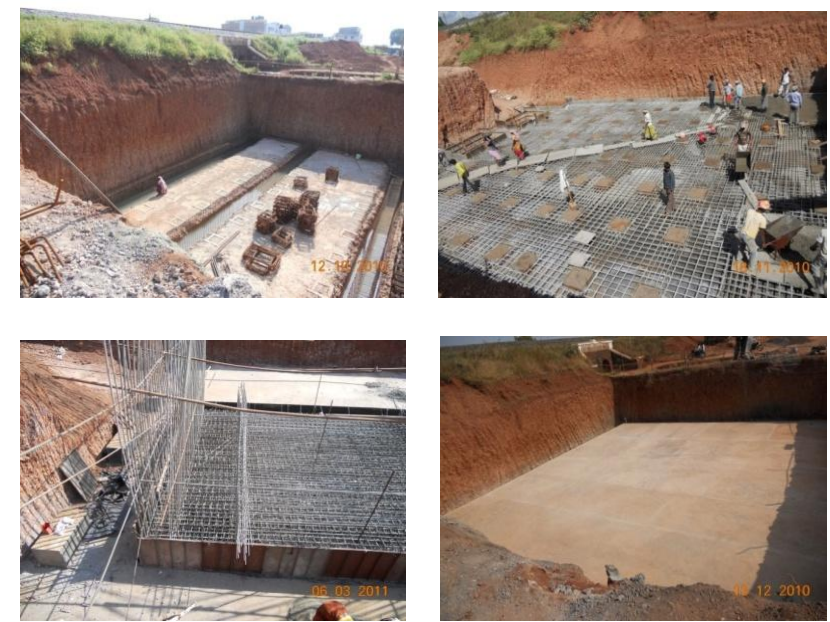

Fig -3: Foundation of road in Box Pushing in RUB.

\subsection{Casting of RCC Box Segments}

Over the well set and leveled thrust bed, RCC box segments are casted. The front face of the box will be cast in a slope to match with the shape of the cutting edge which is fabricated from structural steel and is integrated into the concrete. The cutting edge is provided all round the box and it also acts as a shield preventing soil from top and sides from slipping. A rear shield is provided which houses and guides the subsequent segments while supporting the soil. In case of more than one segment in a span, the necessary recess arrangement with MS plate is provided at pre-determined locations while casting the boxes for accommodating the jacks during pushing. An intermediate cutting shield with MS plate is also required to be provided depending upon site conditions, type of soil, size of box etc
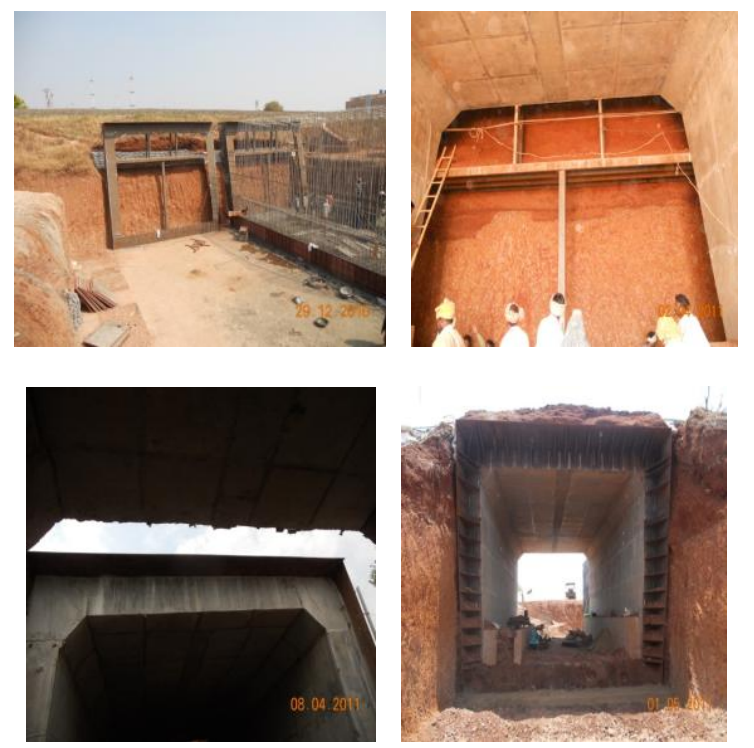

Fig 4: MS Plate/Front Shield for Box Pushing in RUB. 


\subsection{Pushing of Box Segments}

Under suitable speed restriction, the segments are jacked into the embankment by means of hydraulic jacks of suitable capacity installed at the rear end of the segment taking reaction through an assembly of steel pins and beams.

Measures like GI drag sheets are provided to reduce drag effect and lateral movement of overburden. Further epoxy coating on sides and top of the box segments is also applied to reduce the soil friction. In order to reduce the friction between the thrust bed and box segment, two layers of polyethylene sheet sandwiched with a coat of grease is provided. Grid arrangement with rails / channels / timbers etc. was also provided at needy locations to ensure the safety especially in non-cohesive type soils. Controlled blasting with due precautions is also carried out in case where rock is encountered.

The box is jacked into the embankment in a controlled and phased manner with simultaneous excavation of material from inside manual / machinery after every stage of jacking. Throughout the entire process of jacking, alignment is monitored by optical instruments at regular intervals. Rectification of alignment is achieved through jacks. The jacking of segments, in case of more than one in a span, first segment will follow the second segment for each stroke.
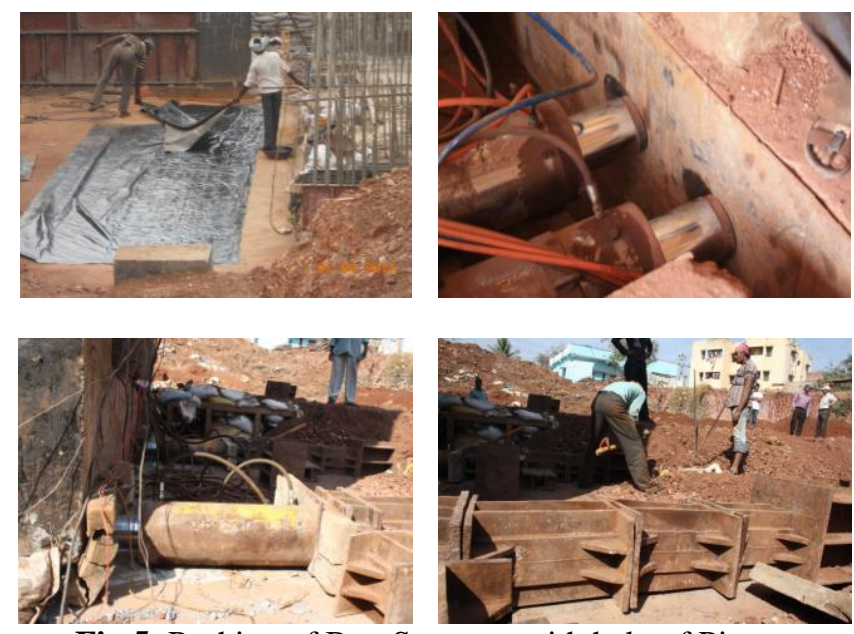

Fig 5: Pushing of Box Segment with help of Piston.

\section{MATERIALS USED}

\subsection{Thrust Bed}

The thrust bed mainly consists of thrust wall, thrust bed with pin pockets on bed, keys for additional resistance. The basic feature of the thrust bed is to provide necessary resistance needed for the jacking operation. For this purpose, a welldesigned RCC slab will be constructed outside the bridge with its top level being kept exactly at the proposed bottom level of the RCC box. Thrust bed will have suitable pockets at different locations for housing jacking pins designed for resisting the pushing force exerted by hydraulic jacks as the box is being jacked through the embankment. Over the thrust bed, $50 \mathrm{~mm}$ screed is to be provided to get exact line, level of the bed for pushing operation. At pockets location, precast cover blocks are provided to cover the pin pockets during pushing operation.

\subsection{Front Shield}

It is a MS Plate which is made up of mild steel material and used in the site for cutting the soil surface under the railway track. It has cutting edges in the front which helps to cut the soil and move the box segment easily.

\subsection{Rear Shield}

It is made up of mild steel will be fixed on rear end of the first unit of the box. This is connected to the back side of the RCC box segment which helps the box to move properly with out and tilting under the railway track.

\subsection{Drag Sheets / Epoxy Coating}

Drag sheets are provided at the top of box if required. Or the top of the box is coated with epoxy coating to reduce the friction between the box and the soil.

\subsection{Jacking Operation}

For pushing the box unit, the jacking (if found necessary to control the alignment) will be placed behind the RCC box along the axis of the pockets and the jacking pins will be inserted in pockets of thrust bed. Jacking rig will help in maintaining the alignment of the box.
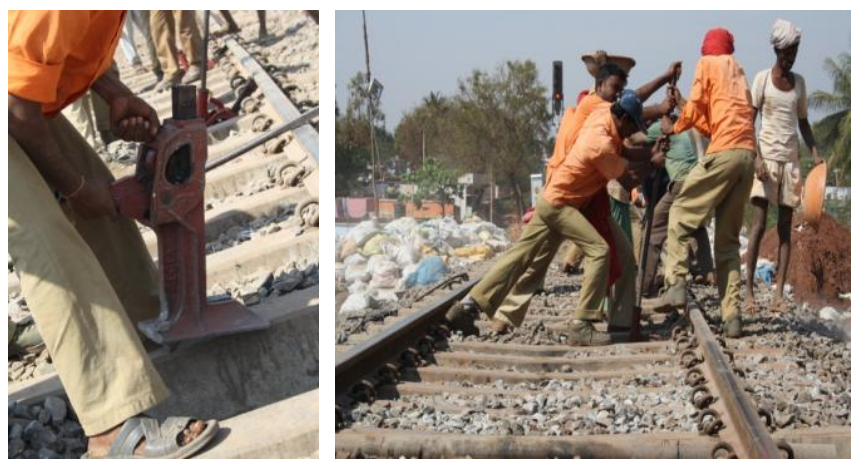

Fig 6: Pushing of Box Segment with help of Piston.

The process of maintaining of proper alignment of railway track when the box segment is pushing under the track is said to be jacking operation.

The jack is used to relocate the track to the original position when the box segment is moving.

While the pushing of first segment is in progress, second segment of the box will be cast on adjacent area of the thrust bed. After complete casting and curing of second box unit, the same will be shifted on the line of alignment of the pushing on thrust bed, the second segment of the box will be positioned in line and level of first box pushed, by suitably operating the hydraulic jacks and joined to the first segment through the rear shield to form the intermediate jacking station (IJS). The IJS also enables pushing of individual units one by one by taking reaction against the rear units, thus reducing the total jacking force needed at a time. For 
pushing of first box, second box will be held at rear by pins and jacks will be provided at IJS.

Pins and jacks will now be shifted on main thrust bed behind second box unit and the second unit will be pushed near shield of the first box unit by hydraulic jacks provision may also kept to place hydraulic jacks in the walls and top slab of the second box which are used for any adjustment of the alignment needed during the jacking operation.

The above process of pushing first segment after excavating and removal of soil and pushing of second segment to close the gap created in IJS as described above will be continued taking care that a minimum overlap of about $200 \mathrm{~mm}$ is always available to the top of front portion of second segment as the rear shield is preventing the soil above and onside of the box. During the process of jacking both units one after the other alignment of the box and level will be checked immediately before and after each pushing operation and in case of misalignment it will be corrected by adjusting the operation of different hydraulic jacks.

\subsection{Plumb Bob}

This is a process to know that the box is moving in the correct position or not.

Axis lines are drawn on the box slab which gives the information of box moment.

\subsection{Piston}

It is a cylindrical machine which is used to push the constructed box to its position in road under bridge.

The pressure which is applied to push the box is of $400 \mathrm{kN}$ to $600 \mathrm{KN}$.

\subsection{Pockets}

Pockets are holes which are made at the construction site and filled with red sand of $70 \mathrm{~cm}$ height before covering up with concrete.

Pockets are used for marking at the construction site after RCC work.

After the RCC work the red sand is removed and counter box is laced in the pockets.

\subsection{Counter Box}

It is an iron rectangular box on $70 \mathrm{~cm}$ height and $800 \mathrm{kgs}$ of weight.

Counter box is placed in pocked for the support of piston.

\subsection{Biscate}

These are used to place in front of the piston which helps to push the constructed box .

\section{ADVANTAGES OF BOX PUSHING}

- No disruption to rail traffic.

- Better quality control.

- Economical
- Time of completion is less.

- Saving in man power \& Machinery.

- No involvement of crane \& heavy equipment.

- Less involvement of other Departments

\subsection{Disadvantages Of Box Pushing}

- Needs trained staff and skilled supervision.

- Imposition of caution order exists for a longer period.

- No scope of night working.

- Once the vertical \& lateral alignment of box disturbed it becomes almost impossible to rectify it.

\subsection{Problems Encountered During Box Pushing}

- Tilting of box.

- Shifting of longitudinal alignment.

- Failure of pin pocket.

- Leaking of joints.

- Occurrence of boulder layer.

- Occurrence of hard rock.

- Occurrence of collapsible strata.

- Unexpected floods during box pushing.

- Disturbance in track geometry.

\section{SELECTION OF SITE DATA}

- Topography of area.

- Detail cross section considering

- Rail level

- Formation level

- Width of embankment Ground level. Route of signaling cables, electric \&telecom cables.

- Nearest river.

- Trail pit bore details, on embankment, on ground level.

\section{CONCLUSIONS}

* Box pushing work means at least partly working in blind, so problems usually come up during execution of work.

* Box pushing work requires close supervision and monitoring and quite often the unsafe conditions develop at these sites.

* Track must be watched regularly to see signs of heaving, settlement, misalignment etc.

* LWR must be cut and site isolated during box pushing.

* Work must be done under block protection / caution order only.

\section{REFERENCES}

[1]. Highway Engineering- S.P.BINDRA, DHANPAT RAI $\&$ SONS- $4^{\text {th }}$ Edition

[2]. Text Book of Railway Engineering- S.C.SAXENA \& S. ARORA, DHANPAT RAI \& SONS- New Delhi

[3]. Dock \& Harbour Engineering- HASMUKH P OZA, GUTAM H OZA

[4]. Principal of traffic and highway engineering- Garbar \& Hoel, Cengage learning

[5]. TRB, 2010 Transportation Research Board (TRB) 
Highway Capacity Manual 2010 (fifth edition) TRB, Washington DC (2010)

[6]. Harkey et al., 2008 D.L. Harkey, S. Raghavan, B. Jongdea, et al. Crash Reduction Factors for Traffic Engineering and ITS Improvement NCHRP Report No. 617 Transportation Research Board, Washington DC (2008) [7]. Robin et al., 2009 T. Robin, G. Antonini, M. Bierlaire, et al. Specification, estimation and validation of a pedestrian walking behavior model Transportation Research Part B: Methodological, 43 (1) (2009), pp. 36-56

[8]. Railway engineering, B.L.Gupta \& Amit Gupta 3rd edition, Reprint 2012

[9]. Bridge Tunnel and Railway Engineering, S.P.Bindra, Latest.

[10]. Railway Works Engineering, M.M.Agarwal, 4th revised edition, Reprint 2014

\section{BIOGRAPHIES}

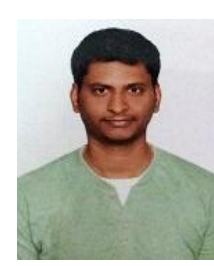

Ranjeet.P holds $M$ Tech Degree in Transportation Engineering from JNTUH, Telangana, India. Presently working as Asst Professor in Civil Department in GNITC, Telangana, India.

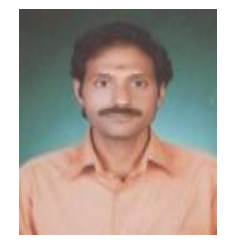

DVS Narashimha Rao, Holds a degree in M sc (Geology), Presently working as Asst Professor in Civil Department in GNITC, Telangana, India.

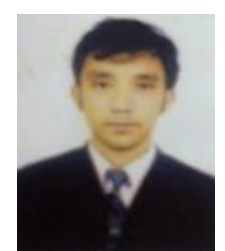

Mohd Akram Ullah Khan, Holds a Master degree in M sc (Geology), Presently working as Asst Professor in Civil Department in GNITC, Telangana, India.

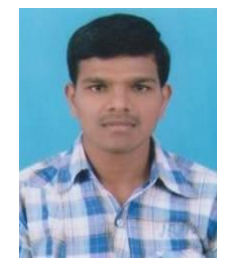

Korakuti Hanumanthu,. Holds M Tech Degree from JNTUA in structural engineering. Presently working as Asst Professor in Civil Department in GNITC, Telangana, India. 